\title{
CARCINOMA PAPILÍFERO DE ALTO RISCO DA GLÂNDULA TIREÓIDE: INFLUÊNCIA DOS FATORES PROGNÓSTICOS EM 126 PACIENTES
}

\author{
HIGH RISK PAPILLARY THYROID CANCER: PROGNOSTIC FACTORS \\ IN 126 PATIENTS
}

\author{
Mauro Marques Barbosa, TCBC-RJ' \\ Geraldo Matos de Sá, TCBC-RJ ${ }^{2}$ \\ Roberto R. M. de Araújo Lima, TCBC-RJ3 ${ }^{3}$ \\ Jacob Kligerman, TCBC-RJ ${ }^{4}$ \\ Terence Pires de Farias ${ }^{5}$ \\ Maurílio José Chagas ${ }^{6}$
}

\begin{abstract}
RESUMO: Objetivo: Este trabalho tem como objetivo avaliar a influência dos fatores prognósticos em portadores de carcinoma papilífero da tireóide, tratados no Hospital do Câncer (INCA-RJ). Método: Com base em testes estatísticos (Wilcoxon e Cox) foram analisados 126 prontuários de pacientes atendidos no período de 1986 a 1994, portadores de carcinoma papilífero da tireóide, pertencentes ao grupo de alto risco, segundo os fatores de risco do carcinoma diferenciado da tireóide, considerando uma sobrevida de dez anos livre de doença. Resultados: Observou-se que 104 pacientes eram mulheres (83\%); a idade variou de sete a 79 anos, média de 40 anos; invasão capsular ocorreu em 15\% (18/126); houve metástase regional em 38\% (47/126) e metástase a distância em $11 \%$ (13/126). A sobrevida em dez anos livre de doença foi de $81 \%$ para os pacientes com menos de 45 anos, e de 76\% para os mais idosos: $\mathrm{p}=0,0008$ (análise univariada) e $\mathrm{p}=0,01$ (análise multivariada). Dos pacientes que tinham invasão capsular, 72\% viveram dez anos, assim como $60 \%$ dos que tinham metástase regional, e $28 \%$ dos que apresentavam metástase a distância. Conclusões: A utilização dos fatores de risco no carcinoma papilífero da tireóide é válida mesmo para doença avançada, sendo também de grande importância na projeção do prognóstico e do futuro desenvolvimento da doença.
\end{abstract}

Descritores: Carcinoma papilífero da tireóide; Fatores prognósticos; Alto risco.

\section{INTRODUÇÃO}

A importância do estudo dos fatores prognósticos no diagnóstico e tratamento dos carcinomas diferenciados da glândula tireóide tem sido demonstrada em grande número de trabalhos publicados na literatura mundial nas últimas duas décadas.

Através dos fatores prognósticos os pacientes podem ser divididos em grupos de baixo e de alto riscos, segundo os parâmetros de idade, tamanho do tumor, ex-

1 Titular da Seção de Cirurgia de Cabeça e Pescoço do Hospital do Câncer (INCA-RJ). Fellow of the American College of Surgeons (FACS). Doutorando em Clínica Cirúrgica pela Faculdade de Medicina da USP

2 Titular da Seção de Cirurgia de Cabeça e Pescoço do Hospital do Câncer (INCA-RJ). Professor Titular do Curso de PósGraduação em Cirurgia de Cabeça e Pescoço da PUC-RJ. Membro da Academia Fluminense de Medicina. Fellow of the American College of Surgeons (FACS).

3 Titular da Seção de Cirurgia de Cabeça e Pescoço do Hospital do Câncer (INCA-RJ)

4 Diretor Geral do Instituto Nacional de Câncer (INCA-RJ). Membro da Academia Nacional de Medicina. Fellow of the American College of Surgeons (FACS).

5 Titular da Seção de Cirurgia de Cabeça e Pescoço do Hospital do Câncer (INCA-RJ)

6 Ex-Médico-Residente da Seção de Cirurgia de Cabeça e Pescoço do Hospital do Câncer (INCA-RJ)

Recebido em 03/11/99

Aceito para publicação em 17/05/2001

Trabalho realizado na Seção de Cirurgia de Cabeça e Pescoço do Hospital do Câncer (INCA-RJ). 
tensão extratireoideana do tumor, e presença de metástases a distância.

A Seção de Cirurgia de Cabeça e Pescoço do Hospital do Câncer (INCa) tem adotado esta divisão em grupos de risco na avaliação prognóstica do carcinoma papilífero da glândula tireóide, mesmo tendo em sua casuística um grande número de pacientes já tratados previamente.

O carcinoma papilífero apresenta-se como o tumor maligno mais freqüente na glândula tireóide, e aquele em que a análise dos fatores prognósticos se mostra mais fielmente relacionada à evolução da doença.

Este trabalho tem por objetivo avaliar a influência dos fatores prognósticos nos casos de carcinoma papilífero em pacientes de alto risco, tratados no Hospital do Câncer (INCa), no período de 1986 a 1994, com base em testes estatísticos e na projeção de sobrevida livre de doença em dez anos (com cálculos atuariais de sobrevida).

\section{MÉTODO}

Foram analisados, retrospectivamente, os prontuários de 126 pacientes portadores de carcinoma papilífero da glândula tireóide, atendidos no Hospital do Câncer (INCa), no período de 1986 a 1994, sendo que muitos destes pacientes já tinham recebido alguma forma de tratamento inicial ao serem encaminhados a nossa instituição, e outros apresentavam doença recidivada.

Os fatores avaliados foram idade, sexo, invasão ou extravasamento da cápsula da glândula tireóide, presença de metástase linfática regional e presença de metástases a distância.

Os testes estatísticos realizados foram o de Wilcoxon para a análise da sobrevida livre de doença das variáveis independentes (análise univariada), e o de Cox na avaliação das variáveis dependentes (análise multivariada).

\section{RESULTADOS}

Quanto ao sexo, observou-se que 104 pacientes (83\%) eram do sexo feminino e 22 (17\%) do masculino, o que representou uma incidência de 5:1.

A faixa etária dos pacientes variou entre sete anos e 79 anos, com a média de 40 anos de idade (Figura 1).

Foi encontrada invasão da cápsula da glândula tireóide em $15 \%$ dos casos, extravasamento da cápsula e invasão dos tecidos vizinhos em $6,3 \%$, metástases linfáticas regionais em $38 \%$, e presença de metástases a distância em $11 \%$ dos pacientes estudados (Tabela 1).

Analisando o fator idade, os pacientes foram divididos em dois grupos: aqueles com menos de 45 anos, e os que tinham mais de 45 anos. Os estudos estatísticos mostraram uma sobrevida livre de doença em dez anos de $81 \%$ para os mais jovens, e de $76 \%$ para os mais idosos, diferença que foi estatisticamente significativa tanto na análise univariada $(p=0,0008)$ quanto na multivariada $(p=0,01)$.

Os pacientes que não apresentavam invasão da cápsula da glândula tireóide pelo tumor sobreviveram dez anos em $84 \%$, enquanto o resultado dos que apresentavam esta invasão foi de $72 \%$, diferença que foi significativa na aná- lise univariada $(\mathrm{p}=0,03)$, mas que não apresentou significância estatística na análise multivariada.

A presença de metástase linfática regional (linfonodos no pescoço) resultou em sobrevida de dez anos de $60 \%$, enquanto nos pacientes que não apresentavam metástases cervicais foi de $90 \%$, o que representou na análise univariada um $p=0,009$ e na multivariada um $p=0,03$, demonstrando a sua importância (Tabela 2).

O fator sexo não apresentou influência estatística, sendo a sobrevida em dez anos para o sexo feminino igual a $80 \%$ e para o sexo masculino de $85 \%$.

As metástases a distância tiveram um papel fundamental na evolução da doença, uma vez que os pacientes sem estas metástases obtiveram sobrevida livre de doença em dez anos de $91 \%$, porém aqueles em que as metástases a distância estavam presentes o resultado foi apenas de $28 \%$, o que foi significativo tanto na forma univariada $(\mathrm{p}=0,00001)$ quanto na multivariada $(\mathrm{p}=0,03)$ (Tabela 3 ).

\section{DISCUSSÃO}

Os fatores prognósticos no câncer papilífero da tireóide vêm sendo usados em muitas instituições no sentindo de dividir os portadores desta doença em grupos de baixo e alto riscos, possibilitando predizer aqueles que terão uma longa sobrevida livre de doença, após tratamento efetivo e bem planejado, e aqueles, que apesar da eficiência da terapêutica empregada, terão resultado final menos animador ou mesmo falho.

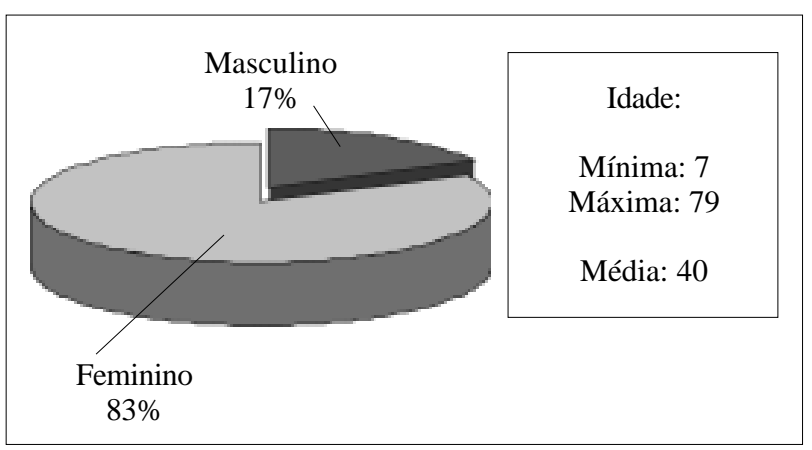

Figura 1 - Incidência quanto ao sexo e à idade. (Fonte: Seção de Cirurgia de Cabeça e Pescoço - Hospital do Câncer/INCa 1999).

Tabela 1

Incidência dos fatores prognósticos avaliados nos casos estudados

$\begin{array}{lc}\text { - Invasão capsular } & 15 \% \\ \text { - Acometimento extratireoidiano } & 6,3 \% \\ \text { - Metástases cervicais } & 38 \% \\ \text { - Metástases a distância } & 11 \%\end{array}$

Seção de Cirurgia de Cabeça e Pescoço - Hospital do Câncer/ INCa -1999. 
Tabela 2

Testes estatísticos dos fatores prognósticos: idade, invasão capsular e metástases cervicais

\begin{tabular}{l|c|c|c}
\hline & $\begin{array}{c}\text { Sobrevida livre } \\
\text { de doença } \\
\text { 10 anos }\end{array}$ & $\begin{array}{c}\text { Univariada } \\
\text { Wilcoxon } \\
p\end{array}$ & $\begin{array}{c}\text { Multivariada } \\
\text { Cox regression } \\
p\end{array}$ \\
\hline Idade & & & 0,01 \\
$\quad<45$ & $81 \%$ & 0,0008 & NS \\
$>45$ & $76 \%$ & & \\
Invasão capsular & $84 \%$ & 0,03 & \\
$\quad$ Não & $72 \%$ & & 0,03 \\
Sim & $90 \%$ & 0,009 &
\end{tabular}

Seção de Cirurgia de Cabeça e Pescoço - Hospital do Câncer/INCa - 1999.

Tabela 3

Influência dos fatores prognósticos: sexo e metástases a distância

\begin{tabular}{l|c|c|c}
\hline Variável & $\begin{array}{c}\text { Sobrevida livre } \\
\text { de doença } \\
10 \text { anos }\end{array}$ & $\begin{array}{c}\text { Univariada } \\
\text { Wilcoxon } \\
p\end{array}$ & $\begin{array}{c}\text { Multivariada } \\
\text { Cox regression } \\
p\end{array}$ \\
\hline Sexo & & & NS \\
Masculino & $85 \%$ & NS & \\
Feminino & $80 \%$ & & 0,03 \\
Met. a distância & $91 \%$ & 0,00001 & \\
Não & $28 \%$ & & \\
Sim & & \\
\hline
\end{tabular}

Seção de Cirurgia de Cabeça e Pescoço - Hospital do Câncer/INCa - 1999

Os fatores prognósticos têm levado em conta a idade do paciente, a extensão local da doença, a presença de linfonodos cervicais comprometidos e a existência de doença metastática a distância.

A importância dos fatores prognósticos nos carcinomas diferenciados da glândula tireóide já é por todos conhecida $1,2,3,4,5,6,7,8$, porém tivemos a intenção de avaliar se estes fatores mantêm seu papel em pacientes encaminhados a uma instituição de tratamento de câncer, o que por si só já propicia uma amostra viciada, pois muitas vezes recebemos pacientes em estágios avançados da doença, e mesmo alguns com tratamentos prévios realizados em outros centros.

Observamos que a idade maior que 45 anos, a presença de metástase linfática cervical, a presença de metástase a distância e a invasão da cápsula da glândula tireóide apresentaram, isoladamente, influência adversa sobre o prognóstico dos pacientes.

A análise multivariada, nos casos do Hospital do Câncer (INCa-RJ) por outro lado, demonstrou que a idade maior que 45 anos $(\mathrm{p}=0,01)$, as metástases a distância $(\mathrm{p}=0,03)$ e as metástases linfáticas regionais $(\mathrm{p}=0,03)$, quando associadas, têm uma participação muito grande na determinação da pior evolução do caso.
A participação das metástases linfáticas regionais no agravamento do prognóstico dos casos avançados por nós estudados talvez seja devida ao fato de terem ocorrido em pacientes com doença em estágios mais graves, pois estudos internacionais têm questionado o papel destas metástases como fator prognóstico nos pacientes com doença inicial ${ }^{9,10}$.

Gostaríamos de chamar a atenção para a importância do fator idade, pois este levantamento demonstrou que mesmo em pacientes com doença avançada, os pacientes mais jovens (com menos de 45 anos) apresentam um prognóstico melhor do que os pacientes mais idosos com doença no mesmo estágio, e que esta influência foi maior do que a exercida pelas metástases a distância, as metástases linfáticas regionais, o sexo do paciente, ou a invasão da cápsula da glândula tireóide pelo tumor ${ }^{11}$.

Podemos concluir deste estudo que a utilização dos fatores prognósticos para o carcinoma papilífero da glândula tireóide mantém a sua validade, mesmo para casos avançados. Apesar desses fatores não interferirem no planejamento terapêutico, pois, por apresentarem neoplasias em estágio clínico avançado devem ser tratados da maneira mais ampla possível, são úteis na projeção do prognóstico e na avaliação do provável desenvolvimento da doença. 
Assumem grande importância na determinação da evolução da doença os fatores idade do paciente, metástase a distância e metástase linfática regional.

Acreditamos que a constatação da influência do fator idade do paciente, mesmo em casos avançados, e por isto já considerados como de alto risco, vem reforçar a importância que devemos dar aos fatores prognósticos do carcinoma papilífero da glândula tireóide, e à filosofia terapêutica que separa os pacientes em grupos de risco $^{12-18}$.

\begin{abstract}
The authors reviewed 126 patients with high-risk papillary thyroid cancer treated at the Hospital do Câncer (Rio de Janeiro) between 1986 and 1994. Hospital do Câncer (Rio de Janeiro - Brazil) is the end point of many patients treated initially elsewhere in the country justifying why patients included in this study were not seen at a first basis. We address the question regarding if prognostic factors of papillary thyroid carcinoma maintain their importance in high stages or recurrent diseases. Patient's age over 45 years, showed an important role on adverse disease evolution $(p=0,01)$, even greater than distant metastasis $(p=0,03)$, cervical metastasis $(p=0,03)$, patient's sex, or glandular capsular invasion. The importance of the patient's age even in a high-risk patients group, reinforces the therapeutic approach of papillary thyroid cancer based on prognostic factors and risk groups.
\end{abstract}

Key Words: Papillary thyroid cancer; Prognostic factors; Risk factors.

\title{
REFERÊNCIAS
}

1. Barbosa MM. Tratamiento Quirúrgico del Carcinoma Diferenciado de Tiroides, no Medular. Tiroidectomia Parcial o Total?. In: Novelli JL, Piazza MV, Sánchez A Patología Quirúrgica de la Glándula Tiroides. UNR Editora, Rosário - Argentina 1997, pp 197-206.

2. Cady B, Sedgwick CE, Meissner WA et al. Risk Factor Analysis in Differentiated Thyroid Cancer. Cancer 1979; 43:810-820.

3. Cady B, Rossi RL. An Expanded View of Risk-group Definition in Differentiated Thyroid Carcinoma. Surgery 1988; 104:947-53.

4. Hay ID, Bergstralh EJ, Goellner JR et al. Predicting Outcome in Papillary Thyroid Carcinoma: Development of a Reliable Prognostic Scoring System in a Cohort of 1779 Patients Surgically Treated at One Institution During 1940 through 1989. Surgery 1993; 114:1050-8.

5. Ruiz de Almodóvar JM, Ruiz-Garcia J, Olea N et al. Analysis of risk of death from differentiated thyroid cancer. Radiother Oncol 1994; 31(3): 207-12.

6. Shaha AR, Shah JP, Loree TR. Risk group stratification and prognostic factors in papillary carcinoma of thyroid. Ann Surg Oncol 1996; 3(6): 534-8.

7. Van Nguyen K, Dilawari RA. Predictive value of AMES scoring system in selection of extent of surgery in welldifferentiated carcinoma of thyroid. Am Surg 1995; 61(2): 151-5.

8. Prendiville S, Burman KD, Ringel MD et al. Tall cell variant: an aggressive form of papillary thyroid carcinoma. Otolaryngol Head Neck Surg 2000; 122(3): 352-

9. Hughes CJ, Shaha AR, Shah JP et al. Impact of Lymph Node Metastasis in Differentiated Carcinoma of the Thyroid: A Matched-pair Analysis. Head \& Neck 1996; 18:127132.

10. Shaha AR, Shah JP, Loree TR. Patterns of nodal and distant metastasis based on histologic varieties in differentiated carcinoma of the thyroid. Am J Surg 1996; 172(6): $692-4$.
11. Coburn MC, Wanebo HJ. Age correlates with increased frequency of high risk factors in elderly patients with thyroid cancer. Am J Surg 1995; 170(5): 471-5.

12. Cady B. Papillary carcinoma of the thyroid gland: treatment based on risk group definition. Surg Oncol Clin N Am 1998; 7(4): 633-44.

13. Loree TR. Therapeutic Implications of Prognostic Factors in Differentiated Carcinoma of the Thyroid Gland. Seminars in Surgical Oncology 1995; 11:246-255.

14. Mazzaferri EL. Impact of Initial Tumor Features and Treatment Selected on the Long-term Course of Differentiated Thyroid Cancer. Thyroid Today 1995; 18:113.

15. Shaha AR, Shah JP, Loree TR. Low-risk differentiated thyroid cancer: the need for selective treatment. Ann Surg Oncol 1997; 4(4): 328-33.

16. Shah JP, Loree TR, Dharker D et al. Lobectomy Versus Thyroidectomy for Differentiated Carcinoma of the Thyroid: A Matched-pair Analysis. Am J Surg. 1993; 166:331-335

17. Taylor T, Specker B, Robbins J et al. Outcome after treatment of high-risk papillary and non-Hurthle-cell follicular thyroid carcinoma. Ann Intern Med 1998; 129(8): 622-7.

18. Wanebo H, Coburn M, Teates D, Cole B. Total thyroidectomy does not enhance disease control or survival even in high-risk patients with differentiated thyroid cancer. Ann Surg 1998; 227(6):912-21.

Endereço para correspondência:

Dr. Mauro M. Barbosa

Av. N. Sra. Copacabana, 897/1.102

CEP: 22060-000 Rio de Janeiro - RJ

e-mail: maurobarbosa@rjnet.com.br 